\title{
Structural Equation Modelling applied to proposed Statistics Attitudes-Outcomes Model: A case of a University in South Africa
}

\author{
Bokang Ncube ${ }^{1,2 *}$, Ntebogang Dinah Moroke ${ }^{1}$ \\ ${ }^{1}$ North West University, South Africa \\ ${ }^{2}$ DST-NRF Centre of Excellence in Mathematical and Statistical Sciences (CoE-MaSS) \\ bokangncube@ymail.com, Ntebo.Moroke@nwu.ac.za
}

\begin{abstract}
The purpose of the study is to investigate the structural relationships among constructs of the statistics attitudes-outcomes model (SA-OM) using exploratory structural equation modelling (ESEM) methodology. The sample consists of 583 first-year undergraduate students enrolled for statistics courses at the university in South Africa. ESEM reveal that all but two of the nine constructs have well to excellent reliability. To enhance the model, we deleted the eight variables. All other indicators have a significant loading into a construct. Congruency of the SA-OM and expectancy value model (EVM) is noted. The SRMR for all modified models are less than 0.10 suggesting that all these models have acceptable fit. Moreover, all the modified models have RMSE values within the ranges of adequate fit. On the contrary, all the models have unacceptable fit according to PCF, CFI, AGFI and PGFI statistics, i.e. according to all parsimony fit indices except the RMSE. The results also reveal that all incremental fit indices but the BBNFI approve the modified models as acceptable since most of these indices are almost equal to a cut-off point of 0.9. However, BBNNI disapprove the ML3 and ML5 models as being acceptable. A host of inconsistencies in fit indices are noted.
\end{abstract}

Keywords: Model fit index, Attitudes and perceptions, Self-Efficacy, Structural equation modelling

\section{Introduction}

Students' achievement in statistics depends heavily on how they learn, understand and apply the course content in their careers of choice. More important is how they perceive the course, the effort they put in, and their ability to deal with its cognitive demands. Generally, one could tell if students have negative attitude towards a course or not. Studies by Carnell (2008), Dempster and McCorry (2009), and Wiberg (2009) suggest timely revision of statistics courses to motivate students. The degeneration of positive to negative perceptions escalate to negative attitudes which inhibit any learning of the course, as well as apprehension and application of the course content. Large bodies of research have focused on these individual constructs' relationship to statistics achievement rather than their interactive and mediating effect on it. Prevention of positive perception, a possibly snowballing into adverse attitudes towards students' statistics achievement becomes imperative. Negative perception often precedes a poor performance in statistics as highlighted by Galli et al. (2010). Very few studies in the area have attempted to uncover causal relationships and covariance among measured and latent variables. This also applies to how development of a positive outlook on statistics can help generate interest, relevance, motivation, effort, and the worth of the course. Most of the studies have focused primarily on relationships between attitudes and achievement, but have not investigated the underlying complex structural relationships (Dempster and McCorry, 2009).

In recent research, factor structure and correlations within structure models have been studied, leaving room for the studies to identify varying variables and constructs. It is for these reasons that an interaction between attitudinal affect and perception constructs, and relevance are viewed as concomitants of statistics achievement. The interaction between these constructs is of interest and there is a need to explore them with a view of suggesting remedial intervention strategies to be implemented at the beginning of every academic year or consistently and concurrently throughout the semesters. Structural Equation Modelling has the capability to do both single-level and multi-level analysis simultaneously, the duty which other first and second generation models failed to do. The method can perform analyses of comparisons of multi-groups using different multivariate techniques such as, multiple regression, multivariate analysis of covariance, confirmatory factor analysis (CFA) to mention a few. 
Structural Equation Modelling (SEM) has the ability to calculate the prediction model and the associated power of analysis, and do path model analysis as well. Thus, SEM in this study helps to remedy deficiencies of past researches on students' attitudes towards statistics by looking at the significance of causal relationships and possible confounding factors that may arise from the model. Specifically, the study aims to confirm underlying perceptions and attitudes constructs derived from ideas gathered from statistics students at a university in South Africa. The primary objective of the study is to determine the effect of students' perceptions and attitudes on statistics achievement or statistics outcome. We hope to be able to analyse causal links between manifest variables and constructs, and further among constructs. Furthermore, the study looks at the relationship between of students' attitudes on their self-efficacy. With SEM, one is able to simultaneously determine parsimony and spuriousness of the final prediction model. Though CFA has been proven to perform similar duties as the SEM (Suhr and Shay, 2009), its limitations have been well documented (see for e.g., Marsh et al., 2004; Hopwood and Donnellan, 2010). This study is expected to contribute to literature by suggesting ways to avert negative attitudes and promote positive perceptions. The results of the study would give an indication of basic constructs that need the instructors' attention. These constructs may be developed in students or used to improve instruction of the statistics subject to ensure students' achievement in related statistics courses. The study will serve as a guide to redesign programmes for statistics for non-majors and for the faculty at this university to relook the entrance requirements for degree programmes offered, paying more attention to how students learn statistics first rather than focus on the pedagogical content of the subject. The study will finally make a significant contribution to the advancement of SEM and its possible application in other disciplines.

\section{Literature Review}

Theoretical Framework: Bad experiences are often a precursor to debilitating statistics anxiety effects on academic achievement. Anxiety emanates not from a lack of proper instruction or training, and insufficient skills (Pan and Tang, 2004). Statistics courses are not only a terrible experience to the majority of non-majors, they also pose a threat to completion on time of their degrees (Onwuegbuzie and Wilson, 2003). Students' misperceptions and little or no proper mathematical background is contributory if not intermediary in students' achievement in statistics (Hulsizer and Woolf, 2009; Pan and Tang, 2004). Anxiety inducing factors are classified into three categories according to Baloğlu (2003). These are dispositional, course-related or situational, and person-related factors. Dispositional factors are emotional and psychological traits of students which include their perceptions, attitudes, and mathematical self-concepts according to Baloğlu (2003) and (Dykeman, 2011). Situational factors according to Onwuegbuzie and Wilson (2003), Pan and Tang $(2004 ; 2005)$ and Dykeman $(2011)$ are dependent on whether the course is mandatory or an elective, prior knowledge of statistical course and mathematical content. There is a growing body of research describing the relationship between students' attitudes towards statistics and statistics achievement (Emmioğlu and Çapa-Aydın, 2011; Sorge and Schau, 2002). Most studies focus on one aspect at a time and do not explore covariation or causality. The current study attempts to address this gap.

A meta-analysis study of students' attitudes toward statistics by (Emmioğlu and Çapa-Aydın, 2011) has cited positive relationships between affect and perceived cognitive competence and course grade. Reported by this study is that course value has a small but positive effect on perceived difficulty. It is evident that with a high correlation between Mathematics and Statistics (Onwuegbuzie and Wilson (2003); Onwuegbuzie, 2003), statistics anxiety may possibly be born from existing and prevalent Mathematics anxiety oftentimes accompanied by negative expectations. Many scholars and educators believe that negative perceptions and attitudes towards Statistics are important in a student's academic life. It is for this particular reason that Schau et al. (1995) developed SATS-28 (with four constructs) and later SATS-36 (with six constructs). Dauphinee et al. (1997) further researched the factor structure of the SATS-28 survey instrument. The instruments' constructs are congruent with Eccles' Expectancy-Value Model's (EVM) theoretical framework (Wigfield and Eccles, 2002; Eccles et al., 2005). Of interest to note is how Eccles' EVM is consistent with SATS36 six components and other variables from the MPSP presented in the appendices, emphasizing the multidimensionality of perceptions, attitudes and motivation. The framework aids instructors and researchers alike to determine the factors that directly or indirectly affect the perception and attitudes of students toward statistics, their achievement related choices and the relationships among them. According to Ramirez et al. (2010), SATS-36 complements Eccles' EVM by demonstrating that some of the constructs are 
relevant to university students' statistics course. The EVM further allows for researchers to determine the interrelation between attitudinal and motivational factors, suggests (Ramirez et al., 2010). This framework additionally gives room for an extension into Statistics and Mathematics domain or other academic domains.

The EVM has been acknowledged as an appropriate instrument and theoretical framework- with its implications in pedagogy, evaluation and research, for investigating the complexity of students' perceptions and attitudes toward statistics subject. There is consistency between the EVM and SATS-36 and selected variables from the MPSP. Ramirez et al. (2010) suggest that when selecting an instrument, instructors and researchers aiming to measure students' perceptions and attitudes towards a statistics subject should consider SATS-36. This is due to its consistency with the EVM and its psychometric properties (Hilton et al., 2004 and Tempelaar et al., 2007). Another model of interest in the Statistics Attitudes-Outcome Model (SAOM) is cited in Ramirez et al. (2012), Emmioğlu and Çapa-Aydın (2012) and Arumugan (2014). The latter applied the PLS algorithm to confirm the SA-OM. The SA-OM is also said to be congruent with many learning theories as it assumes that affective factors, besides cognitive factors play a pivotal role in the students' statistics outcomes attainment. The model is based on the Self-Efficacy theory (Wigfield et al., 2006), SelfDetermination Theory (Deci and Ryan, 2002; Wigfield et al., 2006), and The Theory of Planned Behaviour (Ajzen, 2005). SEM tests, simultaneously, the validity of measures in a model and plausibility of theory (Chin, 1998; Gefen, Straub, and Boudreau, 2000). SEM has its foundations deeply rooted in the classical, path analysis (Wright, 1918) and CFA (Jöreskog, 1966). This text follows a two-step approach first described by Anderson and Gerbing (1988) and later Anderson and Gerbing (1992) and highlighted also by Chin (1998), for performing analysis of covariance structures.

The initial step involves developing an acceptable measurement model using CFA, based on theory and a priori specified causal hypotheses (Mueller and Hancock, 2008). The items' statements and sub-scales mentioned above are shown in appendices. Correlations, multiple regression, etc., cannot test for instrument convergent, discriminant, and nomological validity simultaneously, thus researchers have to follow a 'twostep approach' (Gefen et al., 2000). It is for this reason that the SEM method is followed for this study, as it also offers a solution to the two-step approach (Chin, 1998), with its capability to test convergent validity and discriminant validity simultaneously (Chin and Todd, 1995), reduce the likelihood of false negatives (Type 2 errors) (Chin, 1998) and better tests moderators (Lowry and Gaskin, 2014.).

Empirical Evidence: There is growing evidence on literature that points to the positive effect of perceptions on positive attitudes, with achievement in Statistics course. An SEM model including measures of mathematical aptitude, statistics anxiety and attitudes, motivation to learn statistics, and effort was tested by (Lalonde and Gardner, 1993) in predicting Statistics performance. Their study found that there is a direct positive relationship between aptitude and performance, and the relationship is negative in statistics anxiety, which in turn appeared to be positively related to both motivation and performance. The study also found that the path from Statistics anxiety to performance was statistically non-significant. In a replicated study by (Tremblay, Gardner, and Heipel, 2000), contrary to the expected outcome, there was a significant and negative relationship between statistics anxiety to performance, and a negative path from attitudes to anxiety. Misperception of statistics may give rise to consistent and increased avoidance of the subject. Statistics-related stress develops this avoidance, or poor performance on the subject. Cherney and Cooney (2005) in their study revealed that the lower the Mathematics and Statistics perceptions, the lower the final grade. Students' misperceptions about both Statistics and their Mathematical skill (or lack of it thereof) are due to anxiety and do not necessarily emanate from their limited skills or bad instruction received (Pan and Tang, 2004; Onwuegbuzie and Wilson, 2003). Another relevant work is the Anxiety-Expectation Mediation (AEM) model (Onwuegbuzie, 2003) where both statistics anxiety and achievement's expectation were expected to mediate the relationship between cognitive, personality, and person's characteristics, and performance.

Statistics anxiety and achievement are reported to play a pivotal and significant role in mediating the relationship between performance and anxiety, study behaviour, course load, and the number of statistics courses taken in an academic year (see for e.g. Chiesi and Primi, 2009; Chiesi et al., 2011). (Nasser, 2004) study obtained a high positive effect of mathematical aptitude and a lower, but significant, positive effect of attitudes on performance with a SEM approach. Anxiety was also found to be directly and negatively linked to 
attitudes and the path between anxiety and performance was non-significant, consistent with Lalonde and Gardner (1993). These findings were in contrast with Onwuegbuzie's (2003) and Tremblay et al. (2000) studies. Chiesi and Primi (2010) proposed an SEM model where mathematical background affects both mathematical knowledge and attitudes toward Statistics. These two variables influenced statistics anxiety, which in turn was directly related to attitudes and performance. The results showed that both post-test attitudes and mathematical knowledge were directly and positively related to performance, but anxiety only indirectly affected performance through attitudes. The SEM approach showed attitude as the stronger direct predictor of performance, and played a full mediating role in determining the relationship between statistics anxiety and performance. Mathematics background also appeared as a negative predictor of anxiety. Finally, test anxiety was a positively direct predictor of statistics anxiety.

\section{Methodology}

This section discusses the proposed methods by the study and the related pertinent issues governing them. The section also reports and discusses the results.

Data description and assumptions: Used in this study is the altered SATS-36 and MPSP self-administered questionnaires as instruments for data collection from the university first-year undergraduate class who availed themselves for Statistics lectures on that particular day. A proportionate stratified random sampling method was used to select respondents from a population of about 1000 students during the 2015 academic year. Respondents were randomly selected from their respective classes. A random sample was selected within each stratum to make up the final sample of statistics students. The instrument was chosen due to the fact that it had recently been used to assess students' perceptions, attitudes and achievements towards statistics (Emmioğlu, 2011). The psychometric properties of SATS-36 are well documented (e.g. Chiesi and Primi, 2009). The subscales are based on Eccles and Wigfield's (1995) EVM and Sorge and Schau's (2002) statistics attitudes-achievement structural model. The hypothesised model (Figure 1) in the next sections consists of nine latent constructs, as opposed to seven in previous studies.

Sample size: Structural equation modelling is based on large sample theory (Lehmann, 1999), and minimum sample requirement is asserted to reliably conduct an SEM study. The reader is reminded that the initial step involves finding an acceptable measurement model using confirmatory factor analysis (CFA) (Mueller and Hancock, 2008). Some authors recommend a sample of minimum 200 observations while others say a threshold of 300 is more appropriate. According to Hair et al. (2010), a sample size of 50 observations suffices under ideal conditions using maximum likelihood estimation (MLE). However, Hair et al. highlighted that a sample size of 200 provide a sound basis for estimation. Researchers vary in their elucidations, in terms of the number of cases required. Ratios of 5:1 (about 200 cases) and 2:1 (about 100 cases) respectively of subjects to variable are proposed by Kline (2011). The sample size for the present study is 583 from four first year Statistics classes. This sample size is in agreement with Hair et al. sample size requirements and fulfils the minimum sample and ratio of subjects per variable requirements (Kline, 2011). The observed KMO 0.884 reported in Table 1 further confirmed that the sample used in this study is adequate and suitable for the proposed methods. Pett et al. (2003) recommended a sample adequacy measure of at least 0.70 to less than 0.80 as middle. Values in excess of 0.80 are meritorious.

Table 1: Factorability and Multivariate Normality

\begin{tabular}{ll}
\hline Mardia's Multivariate Kurtosis & 371.7651 \\
Mean Scaled Univariate Kurtosis & -0.2807 \\
Determinant & $3.704 \mathrm{E}-9$ \\
KMO & 0.884 \\
\hline
\end{tabular}


Multicollinearity and Factorability: One other assumption concerns the extent of correlations between the variables. Though a certain degree of collinearity between the variables is allowed, it is of importance to protect the assumption of multicollinearity. This assumption may not be valid as far as social science, psychometric or psychological data is concerned. This study analyses a psychometric or psychological data and did not check the violation of this assumption as it is highly expected that some or most of the variables are highly correlated. A correlation matrix is not invertible if its determinant is equal to zero, that is, it is not factorable as cited in (Field, 2013). Shown in Table 1 also is that the determinant of the correlation matrix is not zero, but very close to zero. This suggests a hint of multicollinearity but at the same time confirms that the data is factorable.

Normality Assumption: The univariate analysis of data was run, to determine the skewness and kurtosis, this includes their normality. All variables showed no issues with regard to skewness $(<2)$ and kurtosis $<3$, although most variables have a negative kurtosis (platykurtic), that is, the responses are highly dispersed or most responses share about the same amount of frequency. This kind of distribution is less peaked than the mesokurtic (normal) distribution. Table 2 shows the mean scaled univariate kurtosis as -0.2807 , smaller than lower bound of -0.0392 . This is mainly due to leptokurtic cases where most respondents selected four for "Neither agree nor disagree" for most of the items, and sometimes sparseness in responses throughout the questionnaire. Multivariate kurtosis given by Mardia's Multivariate Kurtosis equals 371.7651 in Table 1 also reveals that the data were multivariate kurtose, that is, they presented a multivariable 226 deviation from normality, as this value is expected to be as close to zero as possible. These are no surprising result given the type of data from the behavioural sciences, which is psychometric or 226 psychological in nature.

Table 2: Simple Statistics

\begin{tabular}{|c|c|c|c|c|c|c|c|}
\hline Variable & Mean & Std Dev & Skewness & Kurtosis & Varia & Std DevSkewnes & sKurtosis \\
\hline $\mathrm{A} 1$ & 4.33448 & 2.03482 & -0.32187 & -1.05403 & A26 & $3.994851 .75030-0.01334$ & -0.67270 \\
\hline A2 & 3.61235 & 1.92398 & 24339 & -1.00905 & A27 & 3.715271 .965660 .16716 & -1.09578 \\
\hline A3 & 3.61578 & 1.99481 & 0.16172 & -1.15193 & A28 & $4.185251 .92112-0.09713$ & -1.00375 \\
\hline A4 & 4.06346 & 2.06037 & -0.07127 & -1.273 & A29 & 3.643222 .344760 .19785 & -1.50460 \\
\hline A5 & 3.44940 & 2.16512 & 0.32087 & -1.25 & A30 & $5.507721 .66308-1.11779$ & 0.55642 \\
\hline A6 & 50772 & 2.03057 & 1 & & A31 & $5.485421 .61161-1.03263$ & 0.34828 \\
\hline A7 & 4.08233 & 2.15070 & -0.08 & & A32 & $5.711841 .54963-1.27129$ & 1.00019 \\
\hline A8 & 4.65352 & 1.86485 & -0.46574 & -0.702 & A33 & $5.869641 .64144-1.47186$ & 1.24056 \\
\hline A9 & .31218 & 2.13029 & 0.40782 & -1.21 & A34 & $5.161231 .86432-0.80114$ & -0.38514 \\
\hline A10 & 3.21955 & 2.01792 & 0.445 & & A35 & $4.854201 .97084-0.61226$ & -0.74376 \\
\hline A11 & 3.65180 & 2.17069 & 0.19996 & & A36 & $5.262441 .78426-0.94223$ & 0.05379 \\
\hline A12 & 3.50257 & 2.04828 & 0.31049 & -1.11473 & A37 & $4.994851 .99698-0.71382$ & -0.67509 \\
\hline A13 & 4.25043 & 1.97207 & -0.18965 & -1.03638 & A38 & 3.617502 .183070 .21750 & -1.33372 \\
\hline A14 & 3.60720 & 2.13587 & 0.21252 & & A39 & $4.077192 .04399-0.12766$ & -1.13822 \\
\hline A15 & 3.98456 & 2.10173 & -0.09321 & -1.26 & $\mathrm{~A} 40$ & $4.010292 .08823-0.02392$ & -1.24210 \\
\hline A16 & 3.97256 & 1.80661 & 0.03228 & -0.80254 & A41 & 3.914242 .005020 .02318 & -1.13122 \\
\hline 17 & 3.59177 & 1.94284 & 0.22197 & -0.98429 & P2 & $4.337911 .81083-0.22535$ & -0.81379 \\
\hline A18 & 4.30703 & 2.10548 & -0.21951 & -1.234 & & $4.308751 .84000-0.14288$ & -0.96071 \\
\hline A19 & 3.71355 & 1.99534 & 0.15669 & -1.08543 & & $4.092621 .82244-0.11724$ & -0.95344 \\
\hline A20 & 4.00515 & 1.96664 & -0.01536 & -1.12758 & $\mathrm{P} 12$ & $4.427101 .64695-0.26212$ & -0.45730 \\
\hline A21 & 3.57976 & 2.17058 & 0.26658 & -1.29250 & $\mathrm{P} 13$ & $4.898801 .72561-0.54567$ & -0.44949 \\
\hline A22 & 3.99314 & 1.81913 & -0.00698 & -0.88798 & P14 & $4.567751 .73159-0.37060$ & -0.62890 \\
\hline A23 & 4.45455 & 1.98125 & -0.34740 & -1.05677 & P15 & $4.169811 .81356-0.16043$ & -0.86885 \\
\hline A24 & 4.24357 & 1.87927 & -0.21674 & -0.92476 & P16 & 4.758151.83929-0.48552 & -0.72216 \\
\hline A25 & 3.64494 & 2.02115 & 0.18158 & & & & \\
\hline
\end{tabular}


Structural equation modelling procedure: This section outlines the algorithm to be executed from the sample data to the final structural model. These steps give an account of the steps from model conceptualization to model identification, through to model modification and the final model. Jackson et al. (2009) suggest model modification only when they are theoretically plausible and parsimonious. SEM is an inherently a confirmatory technique, as a result, computing a structural model is based on theoretically conceptualised underlying causal or path model. Maximum likelihood estimation (MLE) method is widely used, and assumes underlying multivariate normality. CFA and SEM assumptions are applied and adhered to in developing the measurement models and later the structural model. In SEM, a multivariate normal distribution determines what parameter estimation method the researcher would use, and the extent to which the parameter estimates are trustworthy. These methods are further used when responding to the researcher's hypotheses and research questions as listed below:

$\mathbf{H}_{\mathbf{1}}$ : Affect has a positive relationship with Cognitive Competence.

$\mathbf{H}_{2}$ : Difficulty has a positive relationship with Cognitive Competence.

$\mathbf{H}_{3}$ : Value is predicted by Interest.

$\mathbf{H}_{4}$ : Affect has a positive relationship with Interest.

$\mathbf{H}_{5}$ : Cognitive Competence has a positive relationship with Interest.

$\mathbf{H}_{6}$ : Difficulty has a positive relationship with Interest

$\mathbf{H}_{7}$ : Interest has a positive relationship with Effort.

$\mathrm{H}_{8}$ : Statistics Anxiety has a relationship with Statistics Outcomes.

$\mathbf{H}_{9}$ : Statistics Anxiety has a relationship with Effort.

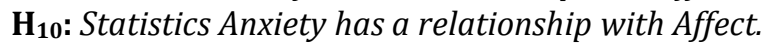

$\mathbf{H}_{11}$ : Statistics Anxiety has a relationship with Difficulty.

$\mathbf{H}_{12}$ : There is a relationship between Statistics Anxiety has a relationship with Interest.

$\mathbf{H}_{13}$ : Difficulty has a relationship with Self-efficacy.

$\mathbf{H}_{14}$ : Effort has a relationship with Self-efficacy.

$\mathbf{H}_{15}$ : Self-efficacy has a relationship with Interest.

$\mathbf{H}_{16}$ : Self-efficacy has a relationship with Value.

$\mathbf{H}_{17}$ : Effort has a positive relationship with Value.

$\mathbf{H}_{18}$ : Effort has a positive relationship with Cognitive Competence.

$\mathbf{H}_{19}$ : Self-Efficacy has a significant positive relationship with Statistics Outcomes.

$\mathbf{H}_{20}$ : Statistics Outcomes is predicted by Value.

$\mathbf{H}_{21}$ : Statistics Outcomes is predicted by Effort.

$\mathbf{H}_{22}$ : Statistics Outcomes has a positive relationship with Cognitive Competence.

$\mathbf{H}_{23}$ : Statistics Anxiety has a positive relationship with Cognitive Competence.

\section{Research questions:}

Research Question 1: Is there is a relationship between the perceptual and attitudinal constructs?

Research Question 2: Is there a relationship between students' attitudes and their self-efficacy?

Research Question 3: Does Statistics Anxiety have a negative effect on a students' Statistics Outcome? 
Figure 1: Modified Hypothesised Structural Model (adopted from Ghulami et al., 2014:12)

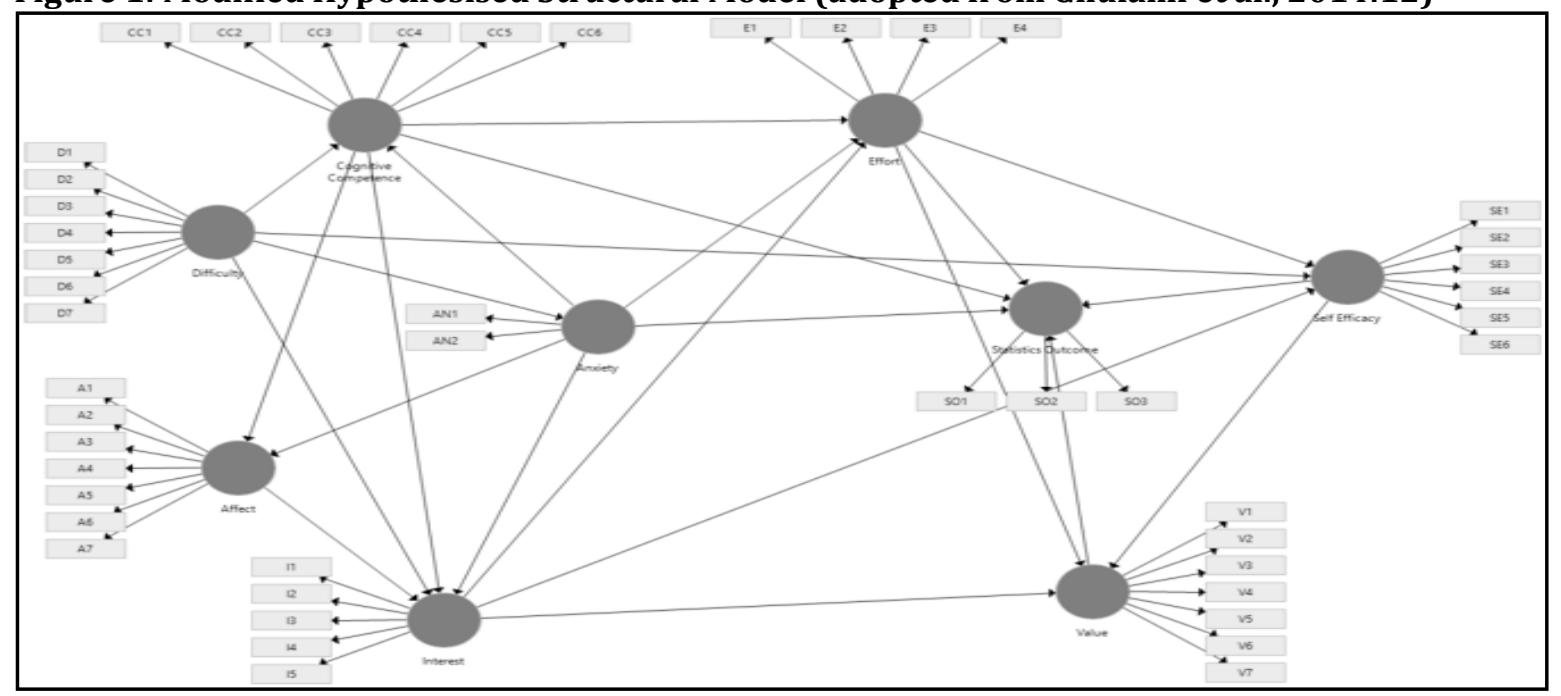

Model Specification: The SEM model is based on relevant theoretical framework outlined under theoretical framework section of this paper. The model is based on the hypothesized model (Figure 1), of which the variables are from a validated SATS-36 and MPSP questionnaires. Confirmatory factor analysis (CFA) ensures as per SATS-36 (Schau, 2003a) that each construct has three or more variables per construct (identified constructs). The exception to this condition is mentioned in Hair et al. (2010), that is, an unidentified construct maybe be seen in analysis involving large samples with many constructs. O'Rourke and Hatcher (2013) outlines the rules to be followed in specifying the model (see Saris et al., 2009).

Model Identification: A topic believed to be most often confusing and difficult in SEM is identification. According to (Suhr, 2006), a model is said to be identified if there exist numerical solutions for every parameter in the model. Estimation is only possible with identified models. A hypothesized model where it is possible to express parameters as functions of variance and covariance of the observed or manifest variables is said to be identified. To attain a solution, number of known parameters in the sample covariance matrix must be greater than or equal to the number of free parameters $q$. This is denoted as $\frac{p^{*}(p+1)}{2}$ where $p$ is the number of measured variables as per sample covariance matrix, $q \leq p *$. A model is just-identified if $q=p *$, that is, a parameter can be estimated through only a single manipulation of the data. If the number of estimated parameters is greater than the unique variance and covariance, where $q>p *$, the model is underidentified. This implies, one or more unique estimations of free parameters are possible from the data. When a model is over-identified, $q<p *$, it implies that free parameters can be estimated in multiple ways from the sample data.

Parameter estimation: The sole aim of parameter estimation is to obtain numerical values for free (unknown) parameters through an estimation technique, as discussed in (Bollen, 1989) for a technical approach, and Ullman (2006) for an applied viewpoint. In SEM, MLE method is widely used. This method is adopted in this study as the sample parameter estimates are approximate in value to the population parameters and robust. The discrepancy function criterion for parameter estimation aims to optimize the difference between the population as estimated sample covariance estimates and the covariance matrix derived from the hypothesised model. The error variance of each latent variable and the parameter value associated with one of the paths from the latent variable to the indicator variable should be fixed at 1.0, suggests (O'Rourke and Hatcher, 2013). The disturbance is on the endogenous latent variable. According to Suhr (2006), the significance of the variable is set at the 0.05 , and the value should exceed $t \geq 1.96$ or 0.10 level of significance if $t \geq 2.56$. Effect size or weight is the value of the path coefficient. Standardised coefficients $\leq 0.10$ may indicate a small effect, values \pm 0.30 a medium effect, and $\geq 0.50$ a large effect. 
Measurement Model Validity: The first stage of SEM is CFA, where a measurement model is estimated through the parameter estimation model and evaluated via the Cronbach's alpha threshold of $\alpha \geq 0.70$. This includes convergence, discriminant, construct and nomological validity. Cronbach's alpha $\geq 0.70$ are employed by the study to assess convergent reliability. Discriminant validity is defined as the extent to which constructs are distinct from one another (Hair et al., 2006); this includes a simple factor structure with virtually no cross-loadings. This is assessed through inter-factor correlations. Nomological validity is the degree to which a construct correlates or covariance with other construct with the structural model (Bagozzi, 1980). It is established when the correlations or covariance within the structural model makes contextual sense (Hair et al., 2006). If the initial or hypothesized model (CFA) fails, i.e. no clear factor structure, EFA is performed followed by iterative exploratory structural equation modelling (ESEM until the best model is selected using the model fit indices.

Model fit assessment: A model of best fit is recognized by looking at individual fit indices for each model during analysis. Several types of these indices have been distinguished by many authors in the last three decades (see Mulaik et al., 1989; Bentler, 1990; Tanaka, 1993; Byrne, 1998), among others. The ability of the hypothesized or a priori model to reproduce the covariance structure of variables of interest is assessed by absolute fit indices (McDonald and Ho, 2002). The other batch of indices concerned with the ability of the hypothesized model to account for the sample data relative to a restricted model which is less complex are called comparative (Miles and Shevlin, 2007) or incremental fit indices. The final batch selects or identifies better fit of a model by an increment of the number of estimated parameters. These are termed parsimonious fit indices. Steiger and Lind (1980) proposed the root mean squared error approximation (RMSEA), which measures the discrepancy between the fitted model and the inferenced covariance matrix of the population. RMSEA value falls within a certain specified confidence value. The model fit indices that are widely used presented in Appendix B, adapted from Hair et al. (2010) show the goodness-of-fit across different model situations. These were based on simulation research that considers model complexity, degrees of error in model specification for different sample sizes (Marsh et al., 2004).

\section{Results}

We run Confirmatory factor analysis on the proposed statistics attitudes-outcomes model (SA-OM) and SATS36 structure. The results summarised in Table 4 are for the hypothesised and modified models. The usual cutoff criterion is used, and is set at absolute 0.3 for factor loadings as cited in (Howell et al., 2012). SAS 9.3 PROC FACTOR with PROMAX rotation resulted in PCF $<0.001$; implying that the null hypothesis that the hypothesised model fits the sample data be rejected in favour of the alternative hypothesis that it does not. The null hypothesis asserts acceptable to good fit if $P C F>0.80$ to 1.00 , respectively, but bad to unacceptable fit if $P C F<0.80$. The results discussed here are with regard to the estimated model as discussed in previous sections.

Hypothesized model: The researcher used MLE to obtain all models in Table 4. Table 4 also presents model assessment indices obtained from the SAS 9.3. According to the output, the hypothesized model indices fall way below the acceptable levels. A $\chi^{2}$ value $<0.0001$ (significant) implies bad model fit. The model has an SRMR that is $>0.08$, RMSEA is $>0.05$ but less than 0.08 suggesting adequate fit, the probability of close fit (PCF) is $<0.0001$ that is a sign of no fit at all. The other fit indices such as the GFI $=0.7040, \mathrm{AGFI}=0.6701, \mathrm{CFI}$ $=0.6783$ and BBNFI $=0.6145$ are below the suggested acceptance value of 0.90 . Owing to the discrepancies reported by the results with only one of the indices (RMSEA) suggesting good fit whilst the rest suggest otherwise. The study concluded that the hypothesised model does not fit the sample data. The next step was to run an exploratory factor analysis (EFA) to determine the factor structure of the sample data. A simple sample factor matrix calculated has eight of the forty-nine redundant loadings, that is, with loadings less than the cut-off value of $|0,3|$. The researcher deleted all such loadings as a result. The study used significant constructs of EFA to fit a modified ESEM model. The results of the modified constructs were found to be acceptable (coefficients more than 0.7) except the "Difficulty' and "Value" constructs which were reported to be mediocre according to Cronbach and Shavelson (2004). 
Table 3: Reliability Results

\begin{tabular}{|c|c|c|c|c|c|}
\hline $\begin{array}{l}\text { Construct } \\
\text { According to } \\
\text { SATS-36/MPSP }\end{array}$ & $\begin{array}{l}\text { Initial } \\
\text { Reliability } \\
\text { values after } \\
\text { CFA }\end{array}$ & Comment & $\begin{array}{l}\text { Construct } \\
\text { after EFA }\end{array}$ & $\begin{array}{l}\text { Reliability } \\
\text { values after } \\
\text { EFA }\end{array}$ & Comment \\
\hline Affect & 0.6181 & Questionable & Affect & 0.8271 & Very good \\
\hline $\begin{array}{l}\text { Cognitive } \\
\text { Competence }\end{array}$ & 0.4252 & Unacceptable & Self-Efficacy & 0.8647 & Very good \\
\hline Difficulty & 0.5511 & Poor & Interest & 0.8709 & Very good \\
\hline Effort & 0.7975 & Good & Effort & 0.7975 & Good \\
\hline Interest & 0.6918 & Questionable & Difficulty & 0.6113 & Questionable \\
\hline Self-Efficacy & 0.8647 & Very good & Motivation & 0.7614 & Good \\
\hline Value & 0.4670 & Unacceptable & Anxiety & 0.8137 & Very Good \\
\hline $\begin{array}{l}\text { Statistics } \\
\text { Outcome }\end{array}$ & 0.5145 & Poor & $\begin{array}{l}\text { Statistics } \\
\text { Outcome }\end{array}$ & 0.7971 & Good \\
\hline Anxiety & 0.4978 & Unacceptable & Value & 0.6370 & Questionable \\
\hline
\end{tabular}

Modified models: This step is a result of under-fitting or over-fitting the hypothesised structural model. The step involves either truncating or re-specifying the model, deleting cases or deleting variables that were marked during the preliminary data analysis process. Due to the unacceptable fit of the hypothesized model. We performed EFA to determine the factor structure of the sample data. We made improvements to the hypothesised model as reported in Table 4. All modified models (ESEM) (ML1-ML7) have a significant chisquare value $<0.0001$, implying bad fit. The SRMR $<0.08$ for acceptable to good fit, whilst the RMSEA ranges between 0.05 and 0.08 for good fit. The result $0.60 \leq P C F<0.0001$ with a small probability implies bad to no fit, whereas $P C F=0.6684$ or $66.84 \%$ suggests a better fit than the rest of the models. The fit indices range from 0.8400 to 0.8806 , obtained from deletion of observations that contributed immensely to the overall negative impact of the kurtosis on data. From the results in Table 4, SRMR for all modified models are less than 0.10 suggesting that all these models have acceptable fit (Hu and Bentler, 1995). Moreover all the modified models have RMSE values within the ranges of adequate fit. On the contrary, all the models have unacceptable fit according to PCF, CFI, AGFI and PGFI statistics, i.e. according to all parsimony fit indices except the RMSE. The results also reveal that all incremental fit indexes but the BBNFI approve the modified models as acceptable since most of these indexes are almost equal to a cut-off point of 0.9. However, BBNNI disapprove the ML3 and ML5 models as being acceptable.

The overall best model is not clear from the results due to inconsistent modification indices across all competing models. Since all standardized linear equations for ML6 (see Appendix C) are statistically significant with $6.7275 \leq t \leq 25.2993$, this means all the indicators of this model are a real measure of the constructs in which they load. The standard errors of the paths equations range between $0.0164 \leq$ standard error $\leq 0.0526$ for ML6. The standardized covariance among exogenous (Factors or Latent) variables represent covariance among constructs in ML6. These showed only two statistically insignificant of the model. The results (in Appendix D) suggest that there is no significant covariance $(t=-0.37519)$ between Factor 1 (Affect) and Factor 5 (Difficulty) and $(t=0.30096$ ) between Factor 4 (Effort) and Factor 7 (Anxiety). This makes ML6 the best candidate model due to fewer statistically insignificant linear equations between indicator and latent variables. These results suggest that when one's affect deteriorates, then statistics subject content becomes difficult. It also means that the more effort students put into dealing with the statistics content, the lesser the anxiety they experience. 
Table 4: Model Fit Assessment under SEM

\begin{tabular}{|c|c|c|c|c|c|c|c|c|}
\hline \multirow[t]{2}{*}{ Index } & \multirow{2}{*}{$\begin{array}{l}\text { Hypothesised } \\
\text { model }\end{array}$} & \multicolumn{2}{|c|}{ Modified model } & \multirow[b]{2}{*}{ ML3 } & \multirow[b]{2}{*}{ ML4 } & \multirow[b]{2}{*}{ ML5 } & \multirow[b]{2}{*}{ ML6 } & \multirow[b]{2}{*}{ ML7 } \\
\hline & & ML1 & ML2 & & & & & \\
\hline $\begin{array}{l}\text { Number of } \\
\text { Variables }\end{array}$ & 49 & 41 & 41 & 41 & 35 & 37 & 41 & 35 \\
\hline $\begin{array}{l}\text { Number of } \\
\text { Cases } \\
\text { Absolute Fit In }\end{array}$ & 583 & 583 & 583 & 583 & 583 & 583 & 448 & 547 \\
\hline$\chi^{2}$ & $<0.0001$ & $<$ & $<$ & $<$ & $<$ & $<$ & $<$ & $<$ \\
\hline SRMR & 0.11327 & 0.0569 & 0.0587 & 0.0673 & 0.0611 & 0.0708 & 0.0585 & 0.0569 \\
\hline GFI & 0.7040 & 0.8574 & 0.8547 & 0.8400 & 0.8622 & 0.8475 & 0.8534 & 0.8589 \\
\hline \multicolumn{9}{|c|}{ Parsimony Fit Indices } \\
\hline AGFI & 0.6701 & 0.8303 & 0.8316 & 0.8171 & 0.8358 & 0.8207 & 0.8301 & 0.8250 \\
\hline PGFI & 0.6579 & 0.7548 & 0.7744 & 0.7689 & 0.7650 & 0.7595 & 0.7733 & 0.7269 \\
\hline RMSEA & 0.0714 & 0.0502 & 0.0518 & 0.0528 & 0.0553 & 0.0571 & 0.0491 & 0.0528 \\
\hline PCF & $<0.0001$ & 0.4391 & 0.1438 & 0.0383 & 0.0040 & $\begin{array}{l}< \\
0.0001\end{array}$ & 0.6684 & 0.0669 \\
\hline \multicolumn{9}{|c|}{ Incremental Fit Indices } \\
\hline CFI & 0.6783 & 0.8741 & 0.8710 & 0.8528 & 0.8728 & 0.8539 & 0.8792 & 0.8751 \\
\hline BBNFI & 0.6145 & 0.8071 & 0.8062 & 07837 & 0.8161 & 0.7946 & 0.7927 & 0.8114 \\
\hline BBNNI & 0.6557 & 0.8570 & 0.8576 & 0.8392 & 0.8566 & 0.8370 & 0.8667 & 0.8525 \\
\hline $\begin{array}{l}\text { BBNNI- rho } \\
1\end{array}$ & 0.5875 & 0.8755 & 0.8721 & 0.8540 & 0.8739 & 0.8552 & 0.8806 & 0.8770 \\
\hline
\end{tabular}

Discussion of Findings: This section discusses the findings in relation to the objectives and the hypotheses. Primarily, this study applied the SEM to investigate the effect of students' perceptions and attitudes on their self-efficacy and statistics outcome. Exploratory and confirmatory factor analyses were applied to the sample data collected during the second semester of the 2015 academic year. Respondents were 538 students registered for first year Statistics modules at the university in South Africa. The findings of this study are intended to give guidance to instructors, policy makers and researchers in identifying variables (including somewhat redundant variables) that need to be developed further, monitored and require student-instructor attention. Moreover, the study has identified shortcomings of large data volumes with many observed variables.

\section{Conclusion}

Research Question 1: Is there is a relationship between the perceptual and attitudinal constructs?

To answer this question, the study considered the SA-OM by Ramirez et al. (2012) which has been deemed congruent to EVM and The Theory of Planned behaviour for selecting variables for use in the study. The study identified the relationships between students' attitudes, their statistics self-efficacy and statistics outcome. The construct validity results have shown the difference in factor structures between the SA-OM and SATS36. From the twenty-three hypotheses tested, only fourteen were supported and were found to be statistically significant owing to the t-values obtained. Construct and convergent validity and reliability of the measures were also examined. According to theory and literature, all the constructs are related. These findings bring a new dimension to the students' attitudes research area, as far as South Africa is concerned.

Research Question 2: Is there a relationship between students' attitudes and their self-efficacy?

The results showed statistical significant relationships between all students' attitudinal indicators measuring their self-efficacy construct. The results confirmed relationship between current statistics self-efficacy and statistics outcome measures and this is consistent with Bandura's (1996) claim as cited in (Finney and Schraw, 2003). This study highlights the fact that students with high self-efficacy may see the relevance of the subject in the degree programme of their choice. 
Research Question 3: Does Statistics Anxiety have a negative effect on a students' Statistics Outcome? Regards to this question, it has been established according to the findings that there is virtually no effect of anxiety on statistics outcomes. This is in contradiction to the findings by Onwuegbuzie $(2000 ; 2004)$, Pan and Tang (2005), Keeley et al. (2008), and Hamid and Sulaiman (2014) that statistics anxiety is a strong predictor of academic performance. It is important to note that a decrease in anxiety throughout a student's academic life has an impact in terms of the heightened perceived usefulness and statistics achievement.

Recommendations: Based on the findings of this study, the following recommendations should be considered.

Implications for Further Research: The current study was based on undergraduate students enrolled in different sections of statistics courses in a public university in South Africa. Therefore, the results do not make general conclusion to the target population of the study outside the country and possibly to the world or other universities in the country. It is suggested that further studies should examine structural relationships in a nation-wide context; so that, the hypothesised relationships can be further generalised by extending the current study to different student populations in developing countries. In addition, the authors suggested that further studies should make cross-cultural comparisons as also suggested by Mvududu's (2003). This may generate new insight into statistical pedagogy. The current study also suggests further studies to use direct measures, such as Mathematics and Statistics tests and quizzes, for assessing students' self-efficacy and statistics outcome. This is consistent with Arumugam's (2014) findings that mathematics achievement and self-efficacy both have a positive significant relationship with statistics outcomes.

Based on the findings we propose to the university to monitor students' attitudes continuously. The proposed relationships generated by the results were static rather than longitudinal. It is suggested that further research should expand on the current study by using a longitudinal design in which the data are collected prior to, during, and after taking statistics courses. For example, Eccles and her colleagues (Eccles and Wigfield, 2002; Wigfield and Eccles, 2000; 2002) suggested that individuals' performances and achievement choices influence their previous achievement-related experiences across time. We suggest further studies that will test their proposal to extend the findings of the current study. Although, the current study revealed that the hypothesized "Statistics Attitudes-Outcomes Model" did not fit well to the data, it does not mean that this model is the only best possible model. We further suggest methodological research to determine the effect of sample size, number of constructs, under-identification of constructs, free parameters and observed variables on the fit of the measurement and structural models. Further studies may also evaluate redundant variables of a valid construct; construct interactions and moderations to determine the gravity of their effect on the overall SEM performance.

We suggest that further research should investigate alternative models. The current study based the hypothesised and tested "Statistics Attitudes-Outcomes Model" on Eccles and colleagues' application of expectancy value theory to mathematics education (Eccles and Wigfield, 1995; 2002; Wigfield and Eccles, 2000). The study also highlighted imminent congruence between the Eccles' Expectancy-Value Framework and the SATS-36 and some MPSP constructs. The data used in this paper explained the adaptation of Eccles' Model to the statistics education context very well. Further studies could expand on the present findings by adapting "Statistics Attitudes-Outcomes Model" to different subject domains. Due to the lack-of-good fit of the model to the data, the study suggest further research be carried out to determine the effect of sample size, validity and reliability on the overall global model fit. This paper used ML and suggests that further research be done using real life data and different estimation methods such as, the weighted least squares (WLS), full information maximum likelihood (FIML), and/or asymptotic distribution free method (ADF).

Implications Practice of Statistics Education: This study has demonstrated that affective domain is important for explaining students' statistics outcomes. As a result, the university should give students' attitudes a high priority when designing and implementing statistics curricula. It is highly important to suggest that students' positive attitudes toward statistics should be among the main goals of the statistics education; and accordingly, a statistics curriculum should involve various instructional practices, which enhance students' positive attitudes toward statistics. The authors also suggest the evaluation of effectiveness 
of the statistics curriculum by assessing students' attitudes toward Statistics as well as by assessing short term and long-term outcomes.

Statistics instructors in universities should enrol for training that will inform them about the importance of their students' attitudes. This also includes how to implement and evaluate the instruction in a way aimed at enhance students' positive attitudes. The study formulates suggestions for instructors to give statistics activities that are interesting, enjoyable and fun for students to participate. This would help students to have more interest and positive affect toward statistics (Lesser and Pearl, 2008). These may range from possible aptitude checks prior to students' registration, continuous remedial mathematics skills classes, and development of students' interest, worth or value, and appreciation of statistics by giving immediate feedback and have them provide solutions to real-life problems statistically in groups and give feedback as suggested by numerous researchers.

Acknowledgements: A special word of gratitude to the Mafikeng Campus of the North West University for financial assistance. The Centre for Excellence in Mathematics and Statistical Sciences (DST-NRF CoE-MaSS) for their monetary support. Opinions expressed and conclusions arrived at are those of the authors and are not necessarily to be attributed to the CoE-MaSS. We would also like to extend our heartfelt gratitude to Schau (2003a) (SATS-36) and Cherney and Cooney (2005) (MPSP) for granting us permission to use their survey instruments.

\section{References}

Ajzen, I. (2005). Attitudes, personality, and behavior. McGraw-Hill Education, United Kingdom.

Anderson, J. C. \& Gerbing, D. W. (1988). Structural equation modelling in practice: A review and recommended two-step approach. Psychological bulletin, 103(3), 411.

Anderson, J. C. \& Gerbing, D. W. (1992). Assumptions and comparative strengths of the two-step approach comment on Fornell and Yi. Sociological Methods \& Research, 20(3), 321-333.

Arumugam, R. N. (2014). Student's Attitude towards Introductory Statistics Course at public universities using partial least square analysis. Interdisciplinary Journal of Contemporary Research in Business, 6(4), $94-123$.

Bagozzi, R. P. (1980). Causal models in marketing. New York: Wiley.

Baloğlu, M. (2003). Individual differences in statistics anxiety among college students. Personality and Individual Differences, 34(5), 855-865.

Bandura, A. (1996). Social cognitive theory of human development. International encyclopaedia of education, 2, 5513-5518.

Bentler, P.M. (1989). EQS, Structural Equations, Program Manual, Program Version 3.0, Los Angeles: BMDP Statistical Software, Inc.

Bentler, P. M. (1990). Comparative fit indexes in structural models. Psychological bulletin, 107(2), 238-246.

Bentler, P. M. \& Bonett, D. G. (1980). Significance tests and goodness of fit in the analysis of covariance structures. Psychological bulletin, 88(3), 588.

Bollen, K. A. (1989). A new incremental fit index for general structural equation models. Sociological Methods \& Research, 17(3), 303-316.

Browne, M. W. \& Cudeck, R. (1993). Alternative ways of assessing model fit. Sage focus editions, 154, 136.

Byrne, B. M. (1998). Structural Equation Modelling with LISREL, PRELIS and SIMPLIS: Basic concepts, applications and programming. Mahwah, New Jersey: Lawrence Erlbaum Associates.

Carnell, L. J. (2008). The effect of a student-designed data collection project on attitudes towards statistics. Journal of Statistics Education, 16(1), 1-15.

Cherney, I. D. \& Cooney, R. R. (2005). Predicting student performance in a statistics course using the mathematics and statistics perception scale (MPSP).

Chiesi, F. \& Primi, C. (2009). Assessing statistics attitudes among college students: Psychometric properties of the Italian version of the Survey of Attitudes toward Statistics (SATS). Learning and Individual Differences, 19(2), 309-313.

Chiesi, F. \& Primi, C. (2010). Cognitive and non-cognitive factors related to students' statistics achievement. Statistics Education Research Journal, 9(1), 6-26. 
Chiesi, F., Primi, C. \& Carmona, J. (2011). Measuring statistics anxiety cross-country validity of the Statistical Anxiety Scale (SAS). Journal of psychoeducational assessment, 29(6), 559-569.

Chin, W. W. \& Todd, P. A. (1995). On the use, usefulness, and ease of use of structural equation modelling in MIS research: a note of caution. MIS quarterly, 2, 237-246.

Chin, W. W. (1998). The partial least squares approach to structural equation modelling. Modern methods for business research, 295(2), 295-336.

Cronbach, L. J. \& Shavelson, R. J. (2004). My current thoughts on coefficient alpha and successor procedures. Educational and psychological measurement, 64(3), 391-418.

Dauphinee, T. L., Schau, C. \& Stevens, J. J. (1997). Survey of attitudes toward statistics: Factor structure and factorial invariance for women and men. Structural Equation Modelling: a multidisciplinary journal, 4(2), 129-141.

Deci, E. L. \& Ryan, R. M. (2002). Handbook of self-determination research. University Rochester press, 2002.

Dempster, M. \& McCorry, N. K. (2009). The role of previous experience and attitudes toward statistics in statistics assessment outcomes among undergraduate psychology students. Journal of Statistics Education, 17(2), 1-7.

Dykeman, B. F. (2011). Statistics anxiety: Antecedents and instructional interventions. Education, 132(2), 441.

Eccles, J. S. \& Wigfield, A. (1995). In the mind of the actor: The structure of adolescents' achievement task values and expectancy-related beliefs. Personality and Social Psychology Bulletin, 21, 215-225.

Eccles, J. S. \& Wigfield, A. (2002). Motivational beliefs, values, and goals. Annual review of psychology, 53(1), 109-132.

Eccles, J. S., O'Neill, S. A. \& Wigfield, A. (2005). Ability self-perceptions and subjective task values in adolescents and children. In What Do Children Need to Flourish? (237-249). Springer, United States.

Emmioğlu, E. (2011). The relationship between mathematics achievement, attitudes toward statistics, and statistics outcomes: A structural equation model analysis. Unpublished doctoral dissertation. Middle East Technical University, Ankara, Turkey.

Emmioğlu, E. \& Çapa-Aydın, Y. (2011). A meta-analysis on students' attitudes toward statistics. A paper presented at the 58th world statistics congress of International Statistical Institute, Dublin, Ireland.

Emmioğlu, E. S. M. A. \& Capa-Aydin, Y. E. S. I. M. (2012). Attitudes and achievement in statistics: A metaanalysis study. Statistics Education Research Journal, 11(2), 95-102.

Field, A. (2013). Discovering statistics using IBM SPSS statistics. Sage publishers.

Finney, S. J. \& Schraw, G. (2003). Self-efficacy beliefs in college statistics courses. Contemporary Educational Psychology, 28(2), 161-186.

Galli, S., Chiesi, F. \& Primi, C. (2010). Assessing Mathematics Competence in Introductory Statistics Courses: An Application of the Item Response Theory: ICOTS8.

Gefen, D., Straub, D. \& Boudreau, M. C. (2000). Structural equation modelling and regression: Guidelines for research practice. Communications of the association for information systems, 4(1), 1-79.

Ghulami, H. R., Ab Hamid, M. R. \& Zakaria, R. (2014). Partial least squares modelling of attitudes of students towards learning statistics. Journal of Quality Measurement and Analysis, 10(1), 1-16.

Hair, J. F., Black, W. C., Babin, B. J., Anderson, R. E. \& Tatham, R. L. (2006). Multivariate data analysis (Vol. 6).

Hair, J. F., Black, W. C., Babin, B. \& Anderson, R. (2010). Multirative Data Analysis: A Global Perspective: Pearson Prentice Hall, New Jersey.

Hamid, H. S. A. \& Sulaiman, M. K. (2014). Statistics anxiety and achievement in a statistics course among psychology students. International Journal of Behavioral Science, 9(1), 55-66.

Hilton, S. C., Schau, C. \& Olsen. J. A. (2004). Survey of attitudes toward statistics: Factor structure invariance and by administration time. Structural Equation Modelling, 11(1), 92-109.

Hopwood, C. J. \& Donnellan, M. B. (2010). How should the internal structure of personality inventories be evaluated? Personality and Social Psychology Review, 14, 332-346.

Howell, D., Husain, A., Seow, H., Liu, Y., Kustra, R., Atzema, C. \& Barbera, L. (2012). Symptom clusters in a population-based ambulatory cancer cohort validated using bootstrap methods. European Journal of Cancer, 48(16), 3073-3081.

Hu, L. T. \& Bentler, P. M. (1995). Evaluating model fit. In R. H. Hoyle (Ed.), Structural Equation Modelling. Concepts, Issues, and Applications, Sage, London.

Hu, L. T. \& Bentler, P. M. (1999). Cutoff criteria for fit indexes iin covariance structure analysis: Conventional criteria versus new alternatives. Structural eqquation modelling. A Multidisciplinary Journal, 6(1), 155. 
Hulsizer, M. R. \& Woolf, L. M. (2009). A guide to teaching statistics: Innovations and best practices (Vol. 10): John Wiley \& Sons.

Jackson, D. L., Gillaspy Jr, J. A. \& Purc-Stephenson, R. (2009). Reporting practices in confirmatory factor analysis: an overview and some recommendations. Psychological methods, 14(1), 6-23.

Jöreskog, K. G. (1966). Testing a simple structure hypothesis in factor analysis. Psychometrika, 31(2), 165178.

Jöreskog, K. G. \& Sorbom, D. (1984). LISREL VI: Analysis of linear structural relationships by the method of maximum likelihood. Mooresville, IN: Scientific Software.

Keeley, J., Zayac, R. \& Correia, C. (2008). Curvilinear relationships between statistics anxiety and performance among undergraduate students: Evidence for optimal anxiety. Statistics Education Research Journal, $7(1), 4-15$.

Kline, R. B. (2011). Convergence of structural equation modelling and multilevel modelling. na.

Lalonde, R. N. \& Gardner, R. C. (1993). Statistics as a second language? A model for predicting performance in psychology students. Canadian Journal of Behavioural Science, 25(1), 108.

Lehmann, E. L. (1999). Elements of large-sample theory: Springer Science \& Business Media, New York.

Lesser, L. M. \& Pearl, D. K. (2008). Functional fun in statistics teaching: Resources, research and recommendations. Journal of Statistics Education, 16(3), 1-11.

Lowry, P. B. \& Gaskin, J. (2014). Partial least squares (PLS) structural equation modelling (SEM) for building and testing behavioural causal theory: When to choose it and how to use it. IEEE Transactions on Professional Communication, 57(2), 123-146.

Marsh, H. W., Hau, K. T. \& Wen, Z. (2004). In research of golden rules: Comment on hypothesis testing approaches to setting cutoff values fit indexes and dangers in over generalizing Hu \& and Bentler's (1999) findings. Structural equation modelling, 11(3), 320-341.

Marsh, H. W. \& Hocevar, D. (1985). Application of confirmatory factor analysis to the study of self-concept: First-and higher order factor models and their invariance across groups. Psychological bulletin, 97(3), 562.

McDonald, R. P. \& Ho, M. H. R. (2002). Principles and practice in reporting structural equation analyses. Psychological methods, 7(1), 64-82.

Miles, J. \& Shevlin, M. (2007). A time and a place for incremental fit indices. Personality and Individual Differences, 42(5), 869-874.

Mueller, R. O. \& Hancock, G. R. (2008). Best practices in structural equation modelling. In J.W Osborne (Ed). Best practices in quantitative methods (488-508) Thousand Oaks, CA Sage.

Mulaik, S. A., James, L. R., Van Alstine, J., Bennett, N., Lind, S. \& Stilwell, C. D. (1989). Evaluation of goodness-offit indices for structural equation models. Psychological Bulletin, 105(3), 430.

Mvududu, N. (2003). A cross-cultural study of the connection between students' attitudes toward statistics and use of constructivist strategies in the course. Journal of Statistics Education, 11(3), 1-17.

Nasser, F. M. (2004). Structural model of the effects of cognitive and affective factors on the achievement of Arabic-speaking pre-service teachers in introductory statistics. Journal of Statistics Education, 12(1), $1-28$.

O'Rourke, N. \& Hatcher, L. (2013). A step-by-step approach to using SAS for factor analysis and structural equation modelling. SAS Institute.

Onwuegbuzie, A. J. (2000). Statistics anxiety and the role of self-perceptions. The Journal of Educational Research, 93(5), 323-330.

Onwuegbuzie, A. J. (2003). Modelling statistics achievement among graduate students. Educational and Psychological measurement, 63(6), 1020-1038.

Onwuegbuzie, A. J. \& Wilson, V. A. (2003). Statistics Anxiety: Nature, etiology, antecedents, effects, and treatments-a comprehensive review of the literature. Teaching in Higher Education, 8(2), 195-209.

Onwuegbuzie, A. J. (2004). Academic procrastination and statistics anxiety. Assessment \& Evaluation in Higher Education, 29(1), 3-19.

Pan, W. \& Tang, M. (2004). Examining the effectiveness of innovative instructional methods on reducing statistics anxiety for graduate students in the social sciences. Journal of Instructional Psychology, 31(2), 149.

Pan, W. \& Tang, M. (2005). Students' perceptions on factors of statistics anxiety and instructional strategies. Journal of Instructional Psychology, 32(3), 205. 
Pett, M. A., Lackey, N. R. \& Sullivan, J. J. (2003). Makiing sense of factor analysis for instrument development in health care research. Sage.

Ramirez, C., Emmioğlu, E., \& Schau, C. (2010). Understanding students' attitudes toward statistics: New perspectives using an Expectancy-Value Model of motivation and the Survey of Attitudes toward Statistics. Paper presented at the Joint Statistical Meetings, Vancouver.

Ramirez, C., Schau, C. \& Emmioğlu, E. (2012). The importance of attitudes in statistics education. Statistics Education Research Journal, 11(2), 57-71.

Saris, W. E., Satorra, A. \& Van der Veld, W. M. (2009). Testing structural equation models or detection of misspecifications. Structural Equation Modelling, 16(4), 561-582.

Schau, C., Stevens, J., Dauphinee, T. L. \& Del Vecchio, A. (1995). The development and validation of the survey of attitudes toward statistics. Educational and psychological measurement, 55(5), 868-875.

Schau, C. (2003a). Students' attitudes: The other important outcome in statistics education. Paper presented at the Proceedings of the Joint Statistical Meetings.

Sorge, C. \& Schau, C. (2002). Impact of engineering students' attitudes on achievement in statistics: A structural model. Paper presented at the annual meeting of the American Educational Research Association. New Orleans.

Steiger, J. H. (1990). Structural model evaluation and modification: An interval estimation approach. Multivariate behavioural research, 25(2), 173-180.

Steiger, J. H. \& Lind, J. M. (1980). Statistically based tests for the number of common factors. Paper presented at the annual meeting for the Psychometric society, Iowa City, IA.

Suhr, D. D. (2006). Exploratory or confirmatory factor analysis? Cary: SAS Institute.

Suhr, D. D. \& Shay, M., (2009). September. Guidelines for reliability, confirmatory and exploratory factor analysis. In Procedure of 2009 Western Users of SAS Conference, San Jose, CA.

Tanaka, J. S. \& Huba, G. J. (1985). A fit index for covariance structure models under arbitrary GLS estimation. British Journal of Mathematical and Statistical Psychology, 38(2), 197-201.

Tanaka, J. S. (1993). Multifaceted conceptions of fit in structural equation models. Sage focuses editions, 154, 10.

Tempelaar, D. T., Schim van der Loeff, S. \& Gijselaers, W. H. (2007). A structural equation model analysing the relationship of students' attitudes toward statistics, prior reasoning abilities and course performance. Statistics Education Research Journal, 6(2), 78-102.

Tremblay, P. F., Gardner, R. \& Heipel, G. (2000). A model of the relationships among measures of affect, aptitude, and performance in introductory statistics. Canadian Journal of Behavioral Science, 32(1), 40.

Ullman, J. B. (2006). Structural equation modelling: Reviewing the basics and moving forward. Journal of personality assessment, 87(1), 35-50.

Wiberg, M. (2009). Teaching statistics in integration with psychology. Journal of Statistics Education, 17(1), 116.

Wigfield, A. \& Eccles, J. S. (2000). Expectancy-value theory of achievement motivation. Contemporary educational psychology, 25(1), 68-81.

Wigfield A. \& Eccles J. S. (2002). The development of competence beliefs and values from childhood through adolescence. In A. Wigfield and J.S. Eccles (Eds.), Development of Achievement Motivation (pp. 92120). Academic Press, San Diego, CA.

Wigfield, A., Eccles, J. S., Schiefele, U. R. R. \& Davis-Keane, P. E. (2006). Development of achievement motivation. Handbook of child psychology, 933-1002.

Wright, S. (1918). On the nature of size factors. Genetics, 3(4), 367.

\section{Appendices}

Appendix A: Items on the Statistics-Outcomes Model

\begin{tabular}{ll}
\hline Constructs & Labels \\
\hline Affect & \\
Af_1 & I like learning about statistics \\
Af_2 & I feel insecure when I have to solve statistics problems \\
Af_3 & I get frustrated with my statistics tests results \\
Af_4 & I am under stress during statistics class
\end{tabular}


Af_5 I enjoy taking statistics courses

Af_6 I am scared by statistics

Af_7 I would deregister statistics anytime

Af_8 I feel anxious when taking a statistics test or examination*

Af_9 I feel anxious when interpreting statistical results to a friend or the lecturer*

CC_1 I have trouble understanding statistics because of the way I think

CC_2 I have no idea of what is going on in this statistics course

CC_3 I make a lot of mathematical errors in statistics

CC_4 I can understand most of the statistical ideas

CC_5 I understand equations related to statistics

CC_6 I find it difficult to understand statistical concepts

Value

V_1 Statistics is not useful in my daily routine

V_2 Statistics is required in my professional training

V_3 Statistical skills will make me more employable

V_4 Statistics is not useful at the workplace

V_5 Statistical thinking is not applicable outside my career/profession

V_6 Use statistics in my everyday life

V_7 Statistics knowledge are rarely applied in daily life

V_8 I have no application for statistics in my future profession

V_9 Statistics is irrelevant in my life

\section{Difficulty}

D_1 Statistics formulas are easy to understand

D_2 Statistics is a complicated subject

D_3 Statistics is a subject quickly learned by most people

D_4 Learning statistics requires a great deal of discipline

D_5 Statistics involves massive computations

D_6 Statistics is highly technical

D_7 Most people have to learn a new way of thinking to do statistics

I_1 I am interested in being able to communicate statistical information to others

I_2 I am interested in using statistics

I_3 I am interested in understanding statistical information

I_4 I am interested in learning statistics

I_5 I do not want to learn to like statistics*

Effort

E_1 I plan to complete all of my statistics assignments

E_2 I plan to work hard in my statistics course

E_3 I plan to study hard for every statistics test

E_4 I plan to attend every statistics class session

\section{Self-Efficacy}

SE_1 Can identify the scale of measurement for a variable

SE_2 Can identify if a distribution is skewed.

SE_3 Can select the correct statistical procedure to be used to answer a question

SE_4 Can communicate statistical results without any problem

SE_5 Can read a value from any statistical table.

SE_6 I am confident that I have mastered introductory statistics material up to this point in the present academic year

SO_1 If I could, I would choose to take another statistics module

SO_2 In the field in which I hope to be employed when I finish school, I will use statistics.

SO_3 As I complete the remainder of my degree program, I will often use statistics

${ }^{*}$ Added items 
Appendix B: Model Fit Indices

\begin{tabular}{|c|c|c|c|}
\hline Category & Index name & $\begin{array}{l}\text { Level of } \\
\text { acceptance }\end{array}$ & Literature \\
\hline & $\begin{array}{l}\text { Standardized } \\
\text { Regression }\end{array}$ & & \\
\hline Factor Loading & Weight & weight 0.6 & Hair et al. (2006) \\
\hline \multirow[t]{3}{*}{ Absolute Fit } & Chisq & $\mathrm{P}>0.05$ & $\begin{array}{l}\text { Wheaton et al. (1977) } \\
\text { Steiger \& Lind (1980), Steiger (1990), Browne }\end{array}$ \\
\hline & RMSEA & RMSEA $<0.08$ & \& Crudeck (1993) \\
\hline & GFI & GFI $>0.9$ & Jöreskog \& Sorbom (1984) \\
\hline \multirow[t]{4}{*}{ Incremental Fit } & AGFI & $>0.9$ & Tanaka \& Huba (1985) \\
\hline & CFI & $>0.9$ & Bentler (1990), Hu \& Beltler (1999) \\
\hline & TLI & $>0.9$ & Bentler \& Bonett (1980) \\
\hline & NFI & $>0.9$ & Bentler (1989) \\
\hline Parsimonious fit & Chisq/df & Chisq $/ \mathrm{df}<5.0$ & Marsh \& Hocevar (1985) \\
\hline
\end{tabular}

The (RMSEA) is said to be bounded below by zero. Steiger (1990) and Browne \& Cudeck (1993) have defined "close fit" of a model, as a model with a RMSEA $\leq 0.05$. RMSEA $\leq 0.05$ can be considered as a good fit, values between $0.05 \leq$ RMSEA $\leq 0.08$ as an adequate fit, and values between $0,08 \leq$ RMSEA $\leq 0,10$ as a mediocre fit, whereas RMSEA values $>0.10$ are not acceptable. Although there is general consensus that RMSEA $\leq 0.05$, for a good model, Hu \& Bentler (1999) suggested an RMSEA $\leq 0,06$ as a cut-off criterion. As a rule of thumb SRMR $\leq 0.05$ suggests a good fit (Hu \& Bentler, 1995), whereas values $<0.10$ may be interpreted as an acceptable model fit.

\begin{tabular}{|c|c|c|c|c|c|c|c|c|c|}
\hline Variable & coefficient & $\begin{array}{l}\text { Std } \\
\text { error }\end{array}$ & t-value & Comment & Variable & coefficient & $\begin{array}{l}\text { Std } \\
\text { error }\end{array}$ & t-value & Comment \\
\hline 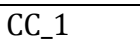 & 0.5362 & 0.0379 & 14.1342 & Significant & Af_9 & 0,7648 & 0,0337 & 22,6636 & Significant \\
\hline CC_2 & 0.6475 & 0.0320 & 20.2061 & Significant & I_1 & 0,7537 & 0,0239 & 31,4826 & Significant \\
\hline CC_-3 & 0.4564 & 0.0415 & 10.9853 & Significant & I_2 & 0,8691 & 0,0167 & 51,8962 & Significant \\
\hline Af_6 & 0.6681 & 0.0309 & 21.6502 & Significant & I_3 & 0,8330 & 0,0189 & 44,1490 & Significant \\
\hline Af_4 & 0,5610 & 0,0367 & 15,2800 & Significant & I_4 & 0,6793 & 0,0287 & 23,7002 & Significant \\
\hline CC_6 & 0,5299 & 0,0382 & 13,8550 & Significant & Af_7 & 0,5274 & 0,0433 & 12,1701 & Significant \\
\hline Af_3 & 0,5966 & 0,0349 & 17,1173 & Significant & $V_{-} 8$ & 0,6294 & 0,0395 & 15,9152 & Significant \\
\hline D_2 & 0,5038 & 0,0395 & 12,7619 & Significant & V_9 & 0,6457 & 0,0391 & 16,5356 & Significant \\
\hline V_1 & 0,4783 & 0,0406 & 11,7768 & Significant & E_1 & 0,5148 & 0,0399 & 12,9151 & Significant \\
\hline Af_2 & 0,4151 & 0,0432 & 9,6088 & Significant & E_2 & 0,8092 & 0,0256 & 31,6344 & Significant \\
\hline$V_{-} 5$ & 0,5275 & 0,0384 & 13,7518 & Significant & E_32 & 0,7808 & 0,0267 & 29,1993 & Significant \\
\hline D_5 & 0,3538 & 0,0526 & 6,7275 & Significant & E_4 & 0,6720 & 0,0320 & 21,0293 & Significant \\
\hline D_6 & 0,5323 & 0,0476 & 11,1807 & Significant & SE_6 & 0,6503 & 0,0302 & 21,5317 & Significant \\
\hline D_7 & 0,4802 & 0,0490 & 9,7912 & Significant & SE_1 & 0,6552 & 0,0299 & 21,9071 & Significant \\
\hline D_4 & 0,6636 & 0,0454 & 14,6238 & Significant & SE_2 & 0,6818 & 0,0283 & 24,0979 & Significant \\
\hline Af_1 1 & 0,7010 & 0,0296 & 23,6453 & Significant & SE-3 & 0,8221 & 0,0191 & 43,0380 & Significant \\
\hline CC_5 & 0,6137 & 0,0345 & 17,7929 & Significant & $\mathrm{SE}_{4} 4$ & 0,8633 & 0,0164 & 52,5067 & Significant \\
\hline Af_5 & 0,7068 & 0,0293 & 24,1063 & Significant & SE_5 5 & 0,6950 & 0,0275 & 25,2793 & Significant \\
\hline CC_4 & 0,6710 & 0,0313 & 21,4123 & Significant & SO_2 & 0,7484 & 0,0275 & 25,3920 & Significant \\
\hline V_- $\overline{6}$ & 0,4699 & 0,0414 & 11,3434 & Significant & SO_3 & 0,8560 & 0,0270 & 31,6876 & Significant \\
\hline Af_e 8 & 0,8693 & 0,0333 & 26,1266 & Significant & & & & & \\
\hline
\end{tabular}


Appendix D: Standardized Results for Covariance among Exogenous Variables

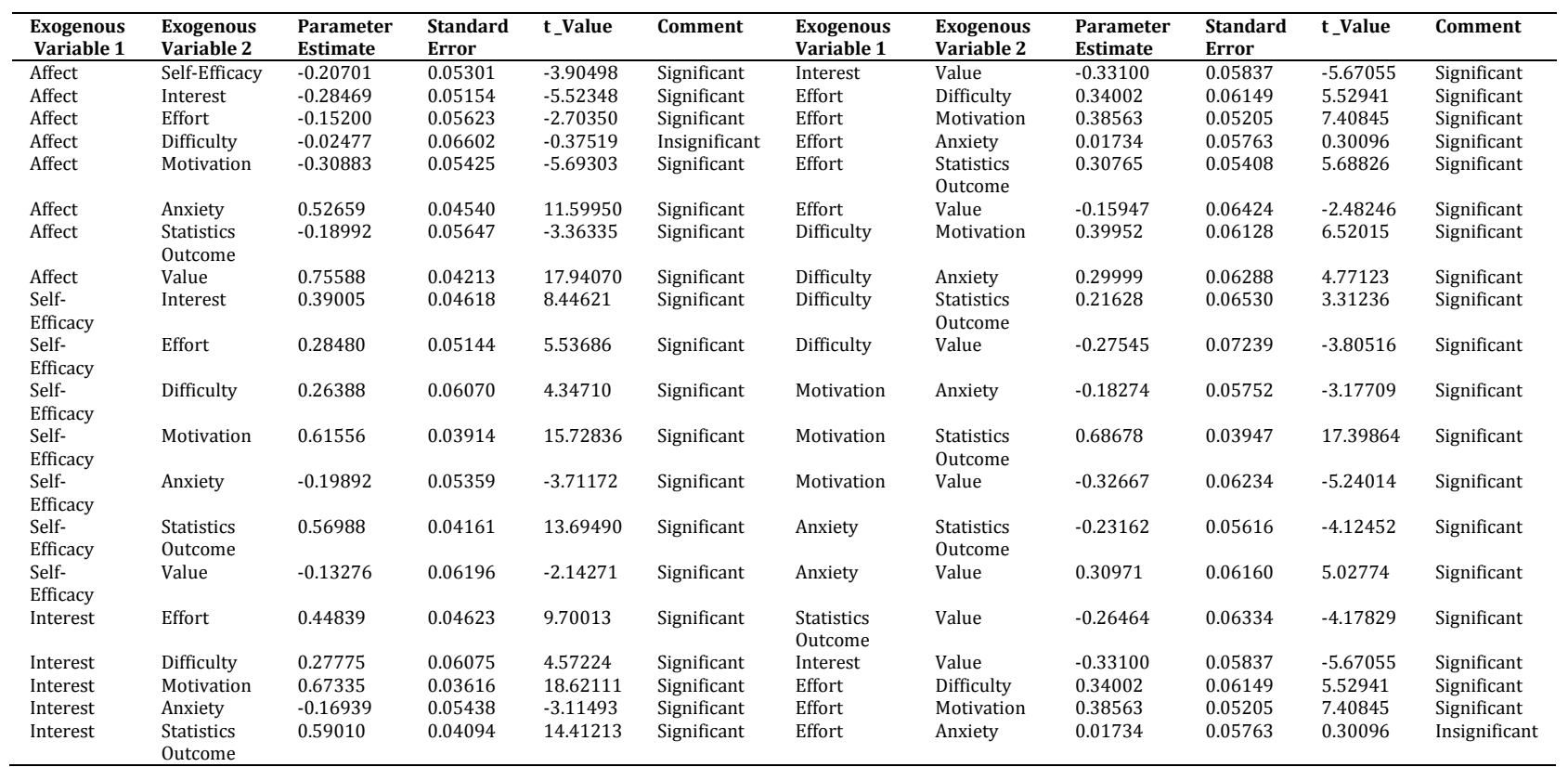

